\title{
A reply from a 'pracademic': It is not all mischief, and there is scope to educate budding authors
}

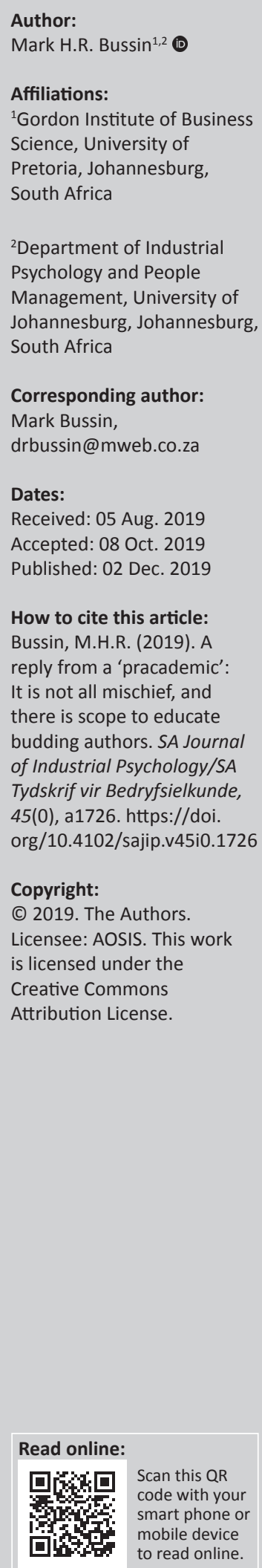

Problemification: Some academics joined the profession from private sector late in their career. They are sometimes referred to fondly as practical academics or 'pracademics' because they still work in private sector and also act as a visiting professor in academia. I sit on eight boards and chair nearly half of them, and serve on audit committees and HR Remuneration committees. I am an example of a 'pracademic', and my induction into academia was one sentence - publish or perish. In the private sector, induction can take up to a week. I had one minute.

Implications: The implication is that I had to find out what a peer-reviewed journal was and trip into the fact that some peer-reviewed journals are scams and others A rated. Telling the difference in my initial years took its toll. I continually had to ask colleagues - is this journal real? Eventually I realised the DHET list was a good starting point and I started submitting articles. I got more rejections than acceptances at first, with very little explanation. So I learnt nothing and did not know what to do to improve. I had to waste another thousand reviewer hours of time to learn what the requirement was.

Research writing is guided by a personal philosophy, and it is about what types of research issues one is inclined towards. For instance, some people are naturally inclined towards basic research and others towards applied research. Others are more oriented towards theory building and testing types for the purpose of creating knowledge for the sake of knowledge. Some others are pragmatic types or realist types and believe real-world problems do not come neatly packaged and are somewhat untidily in presentation calling for discretion or judgement on what to prioritise for research and how to carry out the research. Some are scientist practitioners (evidence informed researchers) and others are practitioner-scientist (practice-led science).

Perhaps this kind of orientation to research is what early career researchers need initially; then, they can worry about reproducibility of research findings down the line after grounding themselves into the research space they perceive to belong to and where they feel invested.

Purpose: The purpose of this opinion article is to share my journey and sow some doubt in reply to the opinion piece circulated by Efendic and Van Zyl. Whilst I do agree with everything that is said in their article, I believe that there is additional information that needs to be considered. Context is important. Not all academics that submit articles have been in academia for many years. We need to do more to support budding authors.

Recommendations: We need to be much more helpful to budding authors than just publishing a page or two called author submission guidelines. These are mostly cosmetic style guides. If we want a higher quality submission and plenty of them - then I believe we need to educate our budding authors of the requirements. Perhaps we need a detailed guide, similar in content and depth as the article of Efendic and Van Zyl (2019). We could consider a podcast setting out the technical guidelines and statistical requirements. Running courses on article publishing by the reviewers is important because that is from the horse's mouth. Trust me; it is not just a case of sticking to the style guide. You need to really understand some of the under currents of article publishing, for example, quoting as many authors from that particular journal's list of articles as possible.

Keywords: Open-science; Article writing; Academic publishing; Article rejection; Publication secrets.

\section{Introduction and context}

This opinion piece is in response to the article written by Efendic and Van Zyl (2019). It sets out a slightly different perspective in the form of a journey of a budding author. Having joined academia late in my career because I am passionate about education and wanted to 'give back', I learnt the hard way on the rules of engagement and how to write an article for a peer-reviewed journal. 
Perhaps because I came from a successful business career, the full-time academics may have over-estimated what I knew about academia. I was told that there was only one rule publish or perish. I was given the names of a few journals and was told to read their style guide. Fortunately, English is my mother tongue, and I thought I understood the style guides perfectly. After about 10 flat-out rejections, I had to try and find out what my colleagues were doing to get published almost first time. I got plenty of advice, but none of it really helped. Eventually, someone suggested that I quote about 10 articles from the journal I want to submit to and that is what led to my first lucky break.

\section{Opinion}

The rejections often gave little information on what I needed to do to improve. Trying another journal that is more suitable did not help much. When reading the article of Efendic and Van Zyl (2019), I was quite shocked that some authors would be so mischievous in manipulating their report data when writing their article. 'Who would go to such lengths to get published', I thought to myself. I would never do what this article reports on. All of my rejections come from my own incompetence and ignorance of the real requirements (the unwritten rules over and above the style guide). So my first reaction to the article was:

1. Whilst I do not dispute the mischief described, I think that the larger portion is ignorance of the requirements. I, for example, learnt so much from reading this, and honestly, I had no idea of some of the requirements.

2. I would guesstimate that there are only a handful of academics in each top university in South Africa that would know the full requirements of the gold standard. This makes the target market in South Africa very small, assuming the top academics publish twice a year and then choose SAJIP. Of course, I acknowledge that SAJIP accepts submissions from everywhere, but it seems that the majority are from South Africa.

3. Just to amplify one of the recommendations - to make these requirements part of the submission process. A mandatory podcast viewing followed by a detailed checklist with a signature would go a long way.

4. I wonder if there was space to discuss a concept called SAJIP Lite - a bit like the JSE and AltX, where the listing requirements are less onerous. It allows budding researchers an opportunity to grow and ideas to percolate. The seasoned researchers could also possibly get many ideas from this and work with the junior researchers to bring the article to SAJIP standards.

5. Perhaps there is a business opportunity to run, say, a morning workshop on how to prepare articles for SAJIP and what the requirements are. It could be marketed across all universities.

6. Lastly, the reviewers of the articles must complete this workshop so they know what they are looking for. I will certainly use the table as a checklist in future! One could even do a mandatory $1 \mathrm{~h}$ podcast by SAJIP Editors where authors have to pay to view it and can only submit an article once they have seen the podcast. I have often had articles rejected with only a very superficial reason - so there is no scope for budding authors to learn. Perhaps we can show the thought leadership you mention to get more publications.

\section{Discussion}

In an article, 'Have referees rejected some of the most cited articles of all times?' by Campanario (1996, p. 1), the author posits that research conducted shows that 'Three of the articles which had problems in being published are the most cited from their respective journals' (p. 1). In trying to understand how this happens D'Andrea \& O'Dwyer (2017) suggest several possible reasons. The main reasons can be summarised as:

1. 'Selfish, narcissistic and cheating reviewers' (D'Andrea \& O'Dwyer, 2017, p. 10) who reject papers that may not agree or support their view or worse still, reject papers that are better than their own work.

2. Editors who reject the paper when one referee or reviewer rejects the paper and another accepts it.

3. Not removing suspicious reviewers from the referee pool.

4. Referee bias with a selfish interest in sabotaging competition.

Of course, there are many other reasons and a whole lot of statistical analysis to demonstrate their point. From my point of view, having received so many rejections, it makes me wonder in hindsight.

Research writing is guided by a personal philosophy, and it is about what types of research issues one is inclined towards. For instance, some people are naturally inclined towards basic research and others towards applied research. Others are more oriented towards theory building and testing types for the purpose of creating knowledge for the sake of knowledge. Some others are pragmatic types or realist types and believe real-world problems do not come neatly packaged and are somewhat untidily in presentation calling for discretion or judgement on what to prioritise for research and how to carry out the research. Some are scientist practitioners (evidence informed researchers) and others are practitioner-scientist (practice-led science).

Perhaps this kind of orientation to research is what early career researchers need initially; then, they can worry about reproducibility of research findings down the line after grounding themselves into the research space they perceive to belong to and where they feel invested.

\section{Conclusion and recommendations}

D'Andrea and O'Dwyer (2017) suggest how to improve the peer-review process that has been around for many years. The main ways are:

1. Blacklist suspect reviewers where a pattern persists.

2. Where there is a tie or even view on accept or reject, use a third blind reviewer.

3. Remove the anonymous status of reviewers.

I would add another one to this list: reviewers should try and recognise if the submission is from a budding author, and they may not have hit the mark, but the paper has potential and 
may even be good. Instead of rejecting the article, suggest the places where it can be improved. I can hear some reviewers say, we do that already. Perhaps, but in my view, not enough.

I have debated whether to follow academic protocol and summarise the conclusion of D'Andrea and O'Dwyer (2017) in my own words, but please forgive the pracademic in me by not reinventing an ending that puts it so well:

In conclusion, peer review in its current format offers little incentive for altruistic behavior from referees, and has limited tools to safeguard the efficiency of the process. Efforts to minimize the number of bad papers accepted must balance the simultaneous goals of also minimizing the number of good papers rejected, and evenly distributing the burden of referee service among all scientists. While keeping in mind that ours is a very simple model, we suggest that editorial strategies can help, but a structural change that rewards good reviewing practices and discourages cheating may have a stronger impact. Although some say peer review is broken and in need of replacement [7, 8], most scholars still hold it in high regard and, while acknowledging the system's flaws, advocate evidence-based efforts to improve it $[18,35]$. In this latter context, future studies using more sophisticated models informed by empirical data should provide a better sense of the quantitative impact of referee and editor bias, and the most effective strategies to counter them. (p. 12)

Thank you for the opportunity to contribute to this debate. I am still left wondering how many of my rejected papers could have been avoided. Just saying ....

\section{Acknowledgements Competing interests}

The author declares that he has no financial or personal relationships that may have inappropriately influenced him in writing this article.

\section{Author's contributions}

M.H.R.B. is the sole author of this research article.

\section{Ethical considerations}

This article followed all ethical standards for a research without direct contact with human or animal subjects.

\section{Funding information}

This research received no specific grant from any funding agency in the public, commercial or not-for-profit sectors.

\section{Data availability statement}

Data sharing is not applicable to this article as no new data were created or analysed in this study.

\section{Disclaimer}

The views and opinions expressed in this article are those of the author and do not necessarily reflect the official policy or position of any affiliated agency of the author.

\section{References}

Campanario, J.M. (1996). Have referees rejected some of the most-cited articles of all times?. Journal of the American Society for Information Science, 47(4) 302-310. https://doi.org/10.1002/(SICI)1097-4571(199604)47:4<302::AID$302-310$.
ASI $6>3.0 . C O ; 2-0$

D'Andrea, R., \& O'Dwyer, J.P. (2017). Can editors save peer review from peer reviewers?. PLoS One, 12(10), e0186111. https://doi.org/10.1371/journal. pone.0186111

Efendic, E., \& Van Zyl, L.E. (2019). On reproducibility and replicability: Arguing for open science practices and methodological improvements at the South African Journal of Industrial Psychology. SA Journal of Industrial Psychology/SA Tydskrif vir Bedryfsielkunde, 45(0), a1607. https://doi.org/ 10.4102/sajip.v45i0.1607 